\title{
A Formação Continuada e suas Implicações na prática pedagógica de professores:
} uma reflexão possível

\author{
Continuing Education and its Implications in the teacher pedagogical practices: a possible \\ reflection
}

La Formación Continua y sus Implicaciones en la práctica pedagógica del profesorado: una posible reflexión

Recebido: 23/02/2021 | Revisado: 02/03/2021 | Aceito: 05/03/2021 | Publicado: 14/03/2021

\author{
Cristiane Cruz de Oliveira Menezes \\ ORCID: https://orcid.org/0000-0002-7137-5147 \\ Universidade Federal do Amazonas, Brasil \\ E-mail: cristiane.olivemenez@gmail.com \\ Dnávia Miranda Neves Lobato \\ ORCID: https://orcid.org/0000-0002-5728-5313 \\ Universidade Federal do Amazonas, Brasil \\ E-mail: dnaviamn@hotmail.com \\ Vera Lúcia Reis da Silva \\ ORCID: https://orcid.org/0000-0003-4166-5386 \\ Universidade Federal do Amazonas, Brasil \\ E-mail: Veluresi@gmail.com
}

\begin{abstract}
Resumo
A formação continuada passou a ser uma das apostas da educação para o desenvolvimento profissional docente, considerando as rápidas mudanças que ocorrem no contexto educacional que requerem dos profissionais investimentos na própria formação. Este artigo refere-se a um recorte da pesquisa de revisão da literatura realizada para a fundamentação de um estudo em andamento em nível de mestrado e se propõe responder as seguintes problemáticas. Qual a relevância da formação continuada para o desenvolvimento das práticas pedagógicas dos professores? E qual é a contribuição da teoria do professor reflexivo na formação continuada? A metodologia foi de natureza qualitativa, a partir do método da revisão da literatura com o aporte da pesquisa bibliográfica e exploratória e, para as análises das informações extraídas de leituras realizadas em trinta artigos que dialogavam o tema em questão. Buscou-se apoio ao método da análise de conteúdo. Assim, o caminho metodológico do estudo permitiu ir em fontes confiáveis que exigem a maior compreensão crítica do pesquisador sobre relatos já existentes. Concluímos, então, que de acordo com o pensamento dos autores estudados: a) estar em constante processo de formação implica em investimento pessoal e é um contributo para a construção da identidade docente; b) a formação continuada é uma necessidade pessoal e institucional que acompanha a trajetória profissional do professor; c) O processo contínuo de formação não se caracteriza como a reciclagem, ou não se limita a uma mera atualização, treinamento ou capacitação do professor; d) A formação continuada requer aprendizagem ao longo da vida; e) Essa formação precisa ser vista como mecanismo de permanente capacitação reflexiva. Portanto, a relevância da formação continuada está na ampliação do conhecimento e na necessidade de reflexão sobre o ensinar e o aprender.
\end{abstract}

Palavras-chave: Formação continuada; Prática pedagógica; Prática reflexiva.

\begin{abstract}
Continuing education has become one of the bets of education for teacher professional development, considering the rapid changes that occur in the educational context that require professionals to invest in their own training. This article refers to a section of the bibliographic research carried out to support a study in progress at the Master's level and proposes to answer the following problems. What is the relevance of continuing education for the development of teachers' pedagogical practices? And what is the contribution of the reflective teacher theory in continuing education? The methodology was qualitative in nature, based on the literature review method with the support of bibliographic and exploratory research and, for the analysis of the information extracted from readings in thirty articles that discussed the theme in question. Support was sought for the content analysis method. Thus, the study's methodological path allowed to go to reliable sources that require the researcher's greater critical understanding of already existing reports. Our conclusion, according to the thought of the studied authors: shows that: a) being in a constant training process implies personal investment and is a contribution to the construction of the teaching identity; b) continuing education is a personal and institutional need that accompanies the teacher's professional trajectory; c) The continuous training process is not characterized as recycling, or is not limited to a simple update,
\end{abstract}


training or qualification of the teacher; d) Continuing education requires lifelong learning; e) This training must be seen as a mechanism for permanent reflexive training. Therefore, the relevance of continuing education is in the expansion of knowledge and the need for reflection on teaching and learning.

Keywords: Continuing education; Pedagogical practice; Reflective practice.

\section{Resumen}

La formación continua se ha convertido en una de las apuestas de la educación para el desarrollo profesional del profesorado, teniendo en cuenta los rápidos cambios que se producen en el contexto educativo y que obligan a los profesionales a invertir en su propia formación. Este artículo se refiere a una parte de la investigación de revisión de la literatura realizada para la fundamentación de un estudio en curso a nivel de maestría y se propone responder a los siguientes problemas. ¿Cuál es la importancia de la formación continua para el desarrollo de las prácticas pedagógicas de los profesores? ¿Y cuál es la aportación de la teoría del profesor reflexivo en la formación continua? La metodología fue de carácter cualitativo, a partir del método de revisión de la literatura con el apoyo de la investigación bibliográfica y exploratoria y para el análisis de la información extraída de las lecturas en treinta artículos que dialogaron el tema en cuestión. Se buscó apoyo al método de análisis de contenido. Así, la trayectoria metodológica del estudio permitió acudir a fuentes fiables que requieren la mayor comprensión crítica del investigador sobre los informes existentes. Concluimos, entonces, que según el pensamiento de los autores estudiados: a) estar en proceso de formación constante implica en inversión personal y es una contribución a la construcción de la identidad docente; b) la formación continua es una necesidad personal e institucional que acompaña la trayectoria profesional del docente; c) el proceso de formación continua no se caracteriza por ser un reciclaje, ni se limita a una mera actualización, entrenamiento o capacitación del docente; d) la formación continua requiere un aprendizaje a lo largo de la vida; e) esta formación necesita ser vista como un mecanismo de capacitación reflexiva permanente. Por lo tanto, la relevancia de la formación continua radica en la ampliación del conocimiento y en la necesidad de reflexionar sobre la enseñanza y el aprendizaje.

Palabras clave: Formación continua; Práctica pedagógica; Práctica reflexiva.

\section{Introdução}

A formação continuada é uma tônica que tem gerado discussões significativas na comunidade acadêmica e científica acerca da formação de professores. Essa temática, segundo Vasconcellos e Bernardo, (2016, p. 208), tem provocado inúmeras produções, sendo um espaço de muita pesquisa." No entanto, o estudo em tela requereu posicionamento de compreensão do que se trata, efetivamente, na área da educação este tema. Diante dessa necessidade, ou seja, de melhor aprofundamento a pesquisa partiu de uma inquietação para o entendimento da construção dessa ação formativa, a partir do olhar de conceitos já formados, através de uma síntese da revisão da literatura.

Neste sentido, o estudo desenvolveu uma análise detalhista sobre o tema, logo de início foi possível evidenciar diálogos que davam visibilidade da importância desse processo para o desenvolvimento e melhorias das práticas pedagógicas dos docentes diante do processo do ensinar e aprender. Essas discussões são atribuídas às novas exigências das demandas atuais em busca de uma educação de qualidade, uma vez que em comprimento aos direitos subjetivos da educação é importante que se leve em consideração, que todos tenham o direito de desfrutar de um ensino de melhor qualidade e essa responsabilidade recai sobre a formação contínua e a qualificação profissional. Isso tem sido um grande desafio para todos os estão inseridos na educação.

Vale destacar que a complexa realidade atual da escola pública, vem sendo bastante questionada quanto a qualidade do ensino. Na atual contemporaneidade, em que o direito a educação tem se expandido, o cenário educacional brasileiro tem se apresentado com turmas, cada vez mais heterogêneas, em que o público em faixa etária regular ou não põe à escola diante de novos e constantes desafios. Diante dessa realidade, não só a escola e sua gestão administrativa, mas, também, o corpo docente tem às vezes se mostrado frágil, frente as demandas que emergem desse contexto e um dos aspectos desafiadores está na formação inicial e continuada, pois se acredita que é uma possibilidade de enfrentamento desses novos desafios. Havendo, portanto, necessidade de práticas pedagógicas que respondam às expectativas didático-metodológicas de turmas diversificadas que requerem dos docentes, postura mais ativa e dinâmica no exercício do ensinar e aprender. 
Diante do exposto, percebe-se que na linha de frente estão os professores que recebem diante de si maior carga de responsabilidade no processo do ensino e aprendizagem, por isso, não é difícil percebermos que o discurso pelo fracasso escolar vem permeado de apontamentos, que culpabilizam os professores. Não que queiramos isentar esses profissionais de suas responsabilidades, contudo, existem outros fatores que precisam ser levados em consideração, não só por parte do micro, mas, por parte do macrossistema educacional. Assim, todos são responsáveis pelo processo educacional em prol de uma educação de mudanças e transformações sociais.

Frente as demandas necessárias se visualizam políticas públicas que incentivem e efetivem programas de formação continuada, uma vez que, o processo formativo acontece, também, nos espaços da escola de forma sistemática e organizada, tendo seu projeto político pedagógico como documento de respaldo para tal formação, como possibilidade de aprimorar e potencializar no chão das escolas ações pedagógicas em que os professores sejam os protagonistas do seu fazer pedagógico, apoiados pela gestão administrativa e pedagógica da instituição.

A formação continuada no sistema educacional é um processo contínuo de relevância para o desenvolvimento profissional docente, principalmente, para aqueles envolvidos diretamente no processo do ensinar e do aprender. Dessa forma, é importante o empenho individual, mas, também, coletivo, no sentido de somar forças para valorização do trabalho docente em que o processo formativo esteja na pauta da gestão escolar, como umas das prioridades a serem concretizadas. Por isso, é importante que a formação continuada esteja sempre na mesa de diálogos em busca de interlocuções abertas e passíveis de serem atendidas, visando mudanças na realidade da escolar.

No entanto, a formação continuada não pode se limitar apenas ou se restringir a uma atualização pontual, pois isto, não combina com as exigências que o processo formativo requer, mas sim com uma intervenção para mudanças nas ações e no fazer docente, ou seja, na prática pedagógica do professor, sobretudo, no contexto da sala de aula, no sentido de promover condições necessárias para a transformação da realidade do ensinar e do aprender. Vale ressaltar que, o processo da formação é um movimento contínuo que não se conclui com a formação inicial, pois deve ser alimentado com novos conhecimentos e saberes necessários à docência.

Diante disso, consideramos que a docência é um processo dinâmico e complexo, portanto se caracterizam pela dinamicidade da sala de aula que recebe um número expressivo de estudantes com diversidade social, cultural e econômica fragilizada. Assim, consideramos que a formação continuada possibilita melhor preparo para o exercício da docência.

Em vista disso, este artigo refere-se a um recorte de uma revisão da literatura realizada para a fundamentação de uma pesquisa em andamento a nível de mestrado e se propõe responder às seguintes problemáticas: Qual a relevância da formação continuada para o desenvolvimento da qualidade do ensino e das práticas pedagógicas dos professores? E qual é a contribuição da teoria do professor reflexivo na formação continuada? Diante da problemática levantada esse trabalho tem o objetivo de possibilitar uma reflexão sobre a prática pedagógica de professores no processo do ensinar e aprender, como também, trazer em foco a formação continuada atrelada a teoria do professor reflexivo como elemento modificador das práticas pedagógicas e da profissionalização do docente.

\section{Caminho Metodológico da Pesquisa}

Trata-se de uma pesquisa de natureza qualitativa, que segundo por Creswell (2007), a investigação qualitativa é um meio de se aprofundar e entender o sentido da importância que os sujeitos ou os grupos constituem as subjetividades e as adversidades sociais e humanas que se apresentam no problema pesquisado.

Desse modo, a pesquisa qualitativa, permite um contato maior entre pesquisador e o pesquisado, uma vez que essa dinâmica de investigação dá possibilidade para o investigador criar estratégias que podem ser flexíveis sobre os procedimentos que serão adotados durante o estudo. Amparada, também por Chizzotti (2013, p.26) quando reflete que "As 
pesquisas qualitativas, por outro lado, não têm um padrão único porque admitem que a realidade é fluente e contraditória, e os processos de investigação dependem também do pesquisador -- sua concepção, seus valores, seus objetivos". Também como aporte buscamos Pereira et al. (2018, p.67) que descreve: "Os métodos qualitativos são aqueles nos quais é importante a interpretação por parte do pesquisador com suas opiniões sobre o fenômeno em estudo.”

Nesta abordagem, o importante é a objetivação, pois durante a investigação científica é preciso reconhecer a complexidade do objeto de estudo, rever criticamente as teorias sobre o tema, estabelecer conceitos e teorias relevantes, usar técnicas de coleta de dados adequadas e, por fim, analisar todo o material de forma específica e contextualizada.

Diante do contexto, o estudo também, requereu técnicas e instrumentos que ajudassem a responder a problemática levantada durante a pesquisa e, que fossem viáveis durante a coleta dos dados, possibilitando ao pesquisador levantar informações substanciais e necessárias para a investigação. Dessa forma, a pesquisa exploratória serviu como aporte porque, "são desenvolvidas com o objetivo de proporcionar visão geral, de tipo aproximativo, acerca do determinado fato". (Gil,2008, p.27), e a pesquisa bibliográfica que implica na união de procedimentos que procuram soluções, vigilante ao objeto de estudo e, que por isso não se caracterizam como aleatória. Assim, a pesquisa bibliográfica proporciona ao pesquisador, ter acesso a diversos dados de inúmeras publicações e, também, ampliar o seu referencial teórico. Além disso, ajuda ampliar o conhecimento prévio sobre o problema a respeito do qual se procura responder.

Para tal atividade, buscou-se apoio na pesquisa bibliográfica e exploratória para os procedimentos de constituição dos dados, fazendo assim, a substancializacão do material coletado para que o trabalho de investigação desse início. Foram feitas as transcrições e apontamentos dos materiais após as leituras, no qual, gerou o processo que passou a constituir um conjugado de significantes, que precisavam ser organizados para a exploração.

Dessa forma, as análises dos dados foram à luz dos referências teóricas selecionados e mencionados no artigo com objetivo de fundamentar e enriquecer a pesquisa, com isso emergiram novos caminhos de significados e sentidos para investigação. Diante disso, o estudo lançou-se ao método da análise de conteúdo, justificado por Bardin (2016, p. 48) como,

Um conjunto de técnicas de análise das comunicações visando obter, por procedimentos sistemáticos e objectivos de descrição do conteúdo das mensagens, indicadores (quantitativos ou não) que permitam a inferência de conhecimentos relativos às condições de produção/recepção (variáveis inferidas) destas mensagens.

Nesse contexto, as análises interpretativas dos dados da pesquisa tiveram como ponto de partida a pré-análise que é a seleção de todos os materiais, que foram selecionados para a formulação de hipóteses, elaboração de objetivos e de indicadores. Na segunda fase se realizou a exploração do material, fazendo-se a codificação, recorte, classificação e categorização das informações extrair de leituras realizadas de trinta artigos que discutiam o processo da formação continuada como relevância para o desenvolvimento de um ensino de qualidade dentro do chão das escolas públicas e das práticas pedagógicas, bem como, os que dialogavam a contribuição da teoria do professor reflexivo na formação continuada.

O terceiro polo realizou-se o tratamento dos resultados, no qual definiu às duas categorias de análise temática de reflexões deste artigo, a partir disso, as informações extraídas foram expostas à inferência e a interpretação, de maneira que pudessem extrair significados em consonância com a discussão explorada nas duas categorias de análise e, com isso responder as problemáticas levantadas por essa pesquisa.

\section{A Importância da Formação Continuada na Prática Pedagógica do Professor}

A literatura educacional tem intensificado as reflexões sobre a formação de professores e isto tem mobilizado discussões e pesquisas sobre a relevância da formação continuada na perspectiva de melhoria da qualidade de ensino. Dessa 
forma, a temática abordada tem provocado diversos entendimentos, que têm sido expostos em vários eventos científicos, intensificando esforços para a melhoria e a construção de novos caminhos para as práticas docentes.

$\mathrm{Na}$ atual contemporaneidade não se concebe mais, como no Pensamento Freireano, uma educação bancária em que o professor deposita os conhecimentos como se a cabeça do estudante fosse uma caixa arquivadora onde não há reciprocidade do saber, tolindo a mente de pensar e ter criticidade sobre o que ouve, ler ou estuda.

Neste sentido, a reflexão sobre a prática docente é salutar para o bom andamento do trabalho do docente, pois é um espaço de se refazer, se reinventar e encontrar soluções mais viáveis para uma aprendizagem significativa. Por isso, há necessidade de pré-disposição por parte do professor em fazer uma análise crítico-reflexiva, que permita perceber o olhar para se e reconheça suas limitações formativas, pois à docência é dinâmica, necessitando de ações mais ativas e efetivas no cotidiano da sala de aula.

Conforme Nóvoa (1992, p.13):

A formação deve estimular uma perspectiva crítico-reflexiva, que forneça aos professores os meios de um pensamento autônomo e que facilite as dinâmicas de auto-formação participada. Estar em formação implica um investimento pessoal, um trabalho livre e criativo sobre os percursos e os projectos próprios, com vista à construção de uma identidade, que é também uma identidade profissional.

Concordamos com o pensamento de que a formação é o caminho mais viável para uma reflexão crítica sobre o fazer pedagógico, esta ação possibilita autonomia para que o professor seja não apenas crítico, mas criativo com autonomia de se fazer e refazer em sua prática pedagógica. Neste sentido, a formação é um contributo para a construção da identidade profissional docente é, o que está se constitui no exercício da profissão, em sala de aula ou em outros contextos da educação formal e não formal, assim, cria uma interação que permite entre os saberes necessários à docência.

É válido salientar que a construção da docência é um processo contínuo e inacabado, portanto, é fundamental que os profissionais que atuam na área da educação estejam inseridos em cursos de formação, de curta ou longa duração, mesmo que estes sejam oferecidos no espaço do trabalho. Por isso, trazer em foco a formação continuada é bastante significativo, pois esse processo está interligado diretamente com a melhoria das práticas pedagógicas e com a profissionalização docente. Como menciona Cunha (2014, p.35):

A formação continuada refere-se a iniciativas instituídas no período que acompanha o tempo profissional dos professores; pode ter formatos e duração diferenciados, assumindo a perspectiva da formação como processo; tanto pode ter origem na iniciativa dos interessados como pode inserir-se em programas institucionais.

Podemos dizer que a profissão, professor requer que aprendizagem da docência se estenda ao longo da vida, ou seja, que busque e continue buscando seu desenvolvimento profissional docente. A formação possibilita meios de progresso e crescimento formativo em área mais, específicas ou em áreas gerais, atitudes como essas podem ser de iniciativas próprias, como reforça o Art. 13 da LDB 9394/96, em umas das incumbências dos professores é que eles participem do seu desenvolvimento profissional, sendo assim, investir em sua própria formação é um dever de quem valoriza sua profissão e de quem tem o compromisso social consigo e com a formação do outro. Bem como, a formação docente também, precisa de mais iniciativas institucionais.

Considerando a importância da formação no processo contínuo do exercício da profissão, a formação continuada é garantida aos profissionais da educação, que em conformidade ao Art. 62-A esta deve ser oferecida no local de trabalho ou em instituições de educação básica e superior, incluindo cursos de educação profissional, cursos superiores de graduação plena ou tecnológicos e de pós-graduação. 
É certo que, a formação de professores, também, esbarra na desvalorização da própria profissão, dessa forma, tem interferido no trabalho e no desempenho profissional, criando, inúmeras incertezas de permanecer ou não neste ofício. Esta situação parece ofuscar a reflexão necessária, na prática docente.

Essa realidade vivenciada pelos professores pode ser um fator de interferência na qualidade do ensino, pois, estes sentindo-se desvalorizados nem sempre estarão motivados para almejarem um nível mais elevado de formação. Portanto, na maioria das vezes não acreditam nas mudanças necessárias para a transformação da realidade em que se encontram. Podemos dizer, que se o professor que está na linha frente do contexto escolar e não fizer a diferença ninguém mais poderá fazer.

Diante do contexto complexo da educação, muito se há por fazer em busca da qualidade do ensino. Isso requer efetiva concretização de políticas públicas voltadas a formação de professores e sua valorização profissional, este é um dos princípios e fins da educação nacional.

A docência requer compromisso pessoal e institucional, por isso todos são responsáveis pelo bom andamento e funcionamento da educação, quer seja nas instâncias micro ou do macro sistema educacional, o que corresponde ao ato da responsabilidade dos que estão inseridos no ambiente escolar. Então, diante do processo do ensinar e do aprender, as práticas pedagógicas mais significativas não se restringem ao papel da mera transmissão de conteúdos que foram historicamente construídos, pois, a função docente deve ir além da prática reprodutivista e mecanicista. Por sua vez, a escola ou as instâncias superiores precisam proporcionar condições nos aspectos estruturais, pedagógicos e econômicos para trabalho docente.

Romper com velhos paradigmas, por certo, não é tarefa fácil, pois tanto os professores quanto a escola precisam abrir caminhos para o novo contexto em que a educação está inserida. Neste sentido, é que visualizamos na formação continuada a possibilidade de mudanças de velhas práticas que não condizem com a realidade da contemporaneidade, que exige criatividade e renovação do pensamento para novas atitudes de transformação. Para Imbernón (2010, p.11) "a formação continuada dos professores, mais do que atualizá-los, deve ser capaz de criar espaços de formação, de pesquisa, de inovação, de imaginação". Segundo Ferreira (2006, p. 20) a "formação continuada hoje precisa ser entendida como um mecanismo de permanente capacitação reflexiva de todos os seres humanos às múltiplas exigências/desafios que a ciência, a tecnologia e o mundo do (não) trabalho colocam [...]”. Nesta perspectiva, a formação acontecerá de maneira permanente e cotidianamente em momentos diversos.

Além disso, a formação continuada solidifica os saberes adquiridos na formação inicial, pois permite ao docente uma vivência da prática a partir da reflexão crítico-teórica que pode acontecer de maneira individual ou em coletividade, levando em consideração as dimensões pessoais e profissionais, como também, os aspectos pertinentes da subjetividade.

A formação continuada não pode ser considerada como uma reciclagem, pois não se trata de reaproveitamento de professores como se fossem produtos prestes a serem descartados. Conforme Silva e Cunha (2018, p.59), "Este termo 'reciclagem' fez parte da concepção tecnicista da educação e, em geral, propunha formações descontextualizadas e generalistas". Ademais, o processo da formação docente, tem uma concepção mais ampla, uma vez que, o conhecimento é dinâmico e por não ser estático e acabado, há necessidade da aprendizagem ao longo da vida, exigindo do professor a compreensão da busca por novos saberes.

Segundo o Catálogo de Orientações Gerais da Rede Nacional de Formação Continuada:

A formação continuada não pode ser reduzida à atualização, menos ainda a um treinamento ou capacitação para a introdução de inovações ou compensação de deficiências da formação inicial. Devido a experiências anteriores, é comum entre os professores considerar programas institucionais como pacotes a serem executados, gerando uma atitude refratária a eles e comprometendo propostas de formação continuada. (Mec/Brasil \& 2006, p.24) 
Neste sentido, é importante que os programas de formação levem em considerações os vários fatores que implicam no desenvolvimento das práticas pedagógicas e no processo do trabalho docente. No pensamento de Lima e Pimenta (2001, p. 65), a formação continuada é "a articulação entre o trabalho docente, o conhecimento e o desenvolvimento profissional do professor, como possibilidade de postura reflexiva dinamizada pela práxis.” Portanto, este pensamento, só ganhará destaque quando houver a relação entre o conhecimento dialogado no processo de formação com a prática do professor e seu desenvolvimento profissional, isso possibilitará interferir no contexto atual, com mudanças que implicam na melhoria da qualidade da educação.

Desse modo, esse processo contribui para transformação das práticas já existentes, bem como, permite o encaminhamento de ações mais efetivas no sentido de melhorar a gestão pedagógica desenvolvida no ambiente escolar. Portanto, é fundamental que o sistema educacional perceba a necessidade de promover espaço para que o professor possa refletir sobre a sua prática e, assim, integrar um movimento de ação-reflexão-ação, entre a teoria e a prática.

Veloso e Sobrinho (2017), afirmam que a formação continuada é uma necessidade do professor, em razão de que os cursos de licenciatura não propiciando o desenvolvendo pleno, de um docente crítico e reflexivo, atento às demandas da sociedade. Neste sentido, a formação inicial não contempla ou não atente as necessidades formativas de quem ingressa em curso formação de professores e que tem projetos de ações educativas para o agir pedagógico de forma mais planejada e sistematizada.

\section{As Implicações da Formação Continuada na Prática Reflexiva do Professor}

É relevante compreender as implicações da formação continuada na prática reflexiva do professor, uma vez que, essa prática é construída no exercício da docência quando se disponibiliza para mudar uma realidade que pode estar aparente ou não. Segundo Barbosa e Fernandes (2018), a visão da teoria do professor reflexivo vai ao encontro da formação continuada, por ser um momento em que a prática do professor está no centro, ou seja, a ação e o conhecimento prático é o foco dessa formação. A proposta da teoria do professor reflexivo elaborada por Schön (1983), se interliga com a formação continuada por possuir elementos relevantes que fortalecem o processo de aprendizagem e desenvolvimento do professor no cotidiano da sala de aula, uma vez que, esse processo formativo procura preparar os professores para refletirem sobre suas ações e, sobre os conhecimentos já adquiridos com a prática.

A concepção da teoria do professor reflexivo faz ruptura com a racionalidade técnica, ou seja, não permitindo o paradigma tradicional, arraigado nas práticas pedagógicas prevalecer no processo do ensinar e do aprender. Isso, quebra uma sequência de práticas mecanicistas, que vem sendo perpassadas há anos, sufocando o ensino significativo e dinâmico. Assim, para Contreras (2002, p.105): O que o modelo de racionalidade técnica como concepção da atuação profissional revela é sua incapacidade para resolver e tratar tudo o que é imprevisível, tudo o que não pode ser interpretado como um processo de decisão e atuação regulado

No comentário desse autor, ressalta que é necessário resgatar e refletir sobre essa relação da teoria do professor reflexivo junto ao processo da formação continuada, porque, essa união potencializa de maneira reflexiva novas metodologias de ensino e aprendizagem e, aprimora as práticas pedagógicas promovendo o protagonismo do professor junto aos seus alunos.

Dessa forma, a teoria de Schön no Brasil iniciou a partir da disseminação das obras de Antônio Nóvoa e Maurice Tardif e, pelo próprio Schön (1983), em que apresentam suas concepções e contribuições para os saberes da docência e na formação profissional dos professores. Assim, esses autores abrem discussões profundas sobre o desenvolvimento de práticas inovadoras no contexto atual da escola e do processo de ensino e aprendizagem dos professores, de modo a formar o 
desenvolvimento cognitivo crítico-reflexivo, afetivo e moral desses indivíduos, para a libertação das amarras introduzidas pela racionalidade técnica, valorização do pensamento do professor a respeito de sua profissão.

Para tanto, trabalhar a teoria do professor reflexivo entrelaçada à formação continuada é resgatar a prática pedagógica como um elemento essencial para a formação do profissional consciente, autônomo e crítico-reflexivo. Barbosa e Fernandes (2018, p. 1793), destacam que "a proposta que Schön sugere que a formação profissional deve ter como base uma 'epistemologia da prática': com valorização da construção de conhecimento no momento da prática profissional, por meio da reflexão, análise e problematização da prática, na prática.” Assim, espera-se que o processo de formação continuada esteja na mesma direção da teoria sugerida por Schön, que proporcione uma formação com perspectivas de apropriação e capacidade de refletir sobre o cotidiano de práticas.

Segundo Imberenón (2001, p.48-49), a formação terá como base uma reflexão dos sujeitos sobre sua prática docente, de modo a permitir que examinem suas teorias implícitas, seus esquemas de funcionamento, suas atitudes etc., realizando um processo constante de auto avaliação que oriente seu trabalho.

Ademais, a formação continuada nessa visão possibilita o docente olhar par si buscando compreender suas atitudes, suas ações, ou seja, o modo de agir no exercício da docência. Essa prática estimula o professor fazer uma análise e problematizar as experiências vivenciadas de maneira centrada. Diante do exposto, é importante entender mais sobre essa ideia de profissional reflexivo desenvolvida por Schön que se pode interpretar os problemas implícitos na prática cotidiana de sala de aula e podem responder diversos problemas do conhecimento tácito e latente que se revelam em ações que muitas vezes são realizadas de maneira mecânica em sala de aula.

Diante deste contexto, recorremos a Contreras (2002), que reforça a ideia do profissional reflexivo se justifica quando o educador se ver diante de situações que não consegue resolver por meio de repertórios técnicos, por exemplo, atividades que são trabalhadas sobre certo assunto de maneira incertas ou instáveis sem aproveitamento de uma reflexão crítica, que incentive a realização de respostas espontâneas e conscientes sobre a prática diária dos saberes da docência. Além disso, é valido lembrar que a prática cotidiana expõe o profissional em situações diversas de conflitos, em que as vezes são apresentados problemas novos ou já vivenciado anteriormente, que leva o profissional à necessidade de buscar entender $\mathrm{e}$ solucionar tal situação. Mas, às vezes, o seu conhecimento é limitado que por isso, a formação continuada, proporciona o confronto mais equilibrado diante das intemperes da profissão.

Para Barbosa e Fernandes (2018, p.12), “a prática reflexiva é capaz de identificar problemas e resolvê-los, além de ser um momento em que o professor aprende, descobre novos conhecimentos, aprimorando sua formação". Por certo, o processo formativo para o exercício da docência é por toda a vida, ou seja, acompanha a trajetória pessoal e profissional do professor. Dessa forma, é possível argumentar a temática desenvolvida neste trabalho em defesa da possibilidade de mudanças e melhorias para a qualidade o ensino através da prática pedagógica do professor.

\section{Considerações Finais}

Com base nas leituras que fundamentaram esta pesquisa, o processo da formação continuada deve estar visualizando a melhoria da qualidade do ensino na escola, promovendo espaços para o desenvolvimento profissional docente e, que estes possam interagir e reconstruir de maneira reflexiva a prática pedagógica direcionando-a para transformações da realidade do escolar. E dessa forma romper com o paradigma tradicional que, ainda, persiste no sistema educacional impregnado em práticas repetitivas e reprodutivas.

É importante, portanto, que a formação continuada seja um contínuo na profissão da docência, uma vez que, a aprendizagem é um processo que acontece ao longo da vida, por isso, o professor é um profissional que precisa está em busca de novos conhecimentos, pois sempre tem algo a ensinar e aprender. Suas atitudes por novas aprendizagens, são, também, 
maneiras que formalizam o aprendizado construído na formação inicial através da teoria e da prática que, certamente, fortalecerá o seu desenvolvimento profissional docente.

Diante do pesquisado, a revisão bibliográfica, evidenciou a importância da formação continuada como um processo possível de reflexão crítica do fazer pedagógico. Podemos então, concluir que de acordo com os pensamentos dos autores estudados: a) estar em constante processo de formação implica em investimento pessoal e é um contributo para a construção da identidade docente; b) a formação continuada é uma necessidade pessoal e institucional que acompanha a trajetória profissional do professor; c) O processo contínuo de formação não se caracteriza como a reciclagem, ou não se limita a uma mera atualização, treinamento ou capacitação do professor; d) A formação continuada requer aprendizagem ao longo da vida; e) Essa formação precisa ser vista como mecanismo de permanente capacitação reflexiva.

Diante do contexto, há evidências teóricas da relevância da formação continuada para as práticas pedagógicas dos professores e para a construção da identidade que os caracteriza como profissional da educação, comprometidos com as mudanças e transformações do contexto escolar onde está inserido. Esse processo contínuo de formação amplia o conhecimento e a necessidade reflexão sobre o ensinar e o aprender.

Assim, espera-se que a presente pesquisa ajude no desenvolvimento de ações reflexivas no processo do ensina e do aprender da prática pedagógica de professores(as) e, com isso, promova reflexões sobre a relevância da formação continuada ser dialogada no chão das escolas públicas. Ressalta-se também, que a mesma desperte em outros pesquisadores, docentes e estudantes o interesse investigativo sobre o tema em questão, possibilitando a difusão de novas ideias, concepções teóricas mais atuais que atuem no desenvolvimento e na aprendizagem tanto, dos alunos como do corpo docente.

\section{Agradecimentos}

Agradecimentos, ao programa de pós-graduação em Ensino, Ciências e Humanidades -PPGCEH e FAPEAM pelo apoio na realização da pesquisa.

\section{Referências}

Barbosa, S. H. P. B., \& Fernandes, M. C. da S. G. (2018). A teoria do professor reflexivo na formação continuada de professores: discurso vazio de conteúdo. Revista Eletrônica de Educação, 12(1), 6-19. http://portal.mec.gov.br/seb/arquivos/pdf/ciencias.pdf.

Bardin, L. (2016). Análise de Conteúdo. Tradução: Luís Augusto Pinheiro: Edições 70.

Brasil. Mistério da Educação. (2006). Rede Nacional de Formação Continuada de Professores de Educação Básica. Brasília: MEC/Secre taria de Educação Básica. http://portal.mec.gov.br/seb/arquivos/pdf/Rede/catalg_rede_06.pdf.

Chizzotti, A. (2013). Pesquisa qualitativa em ciências humanas e sociais. (5a ed.): Vozes.

Contreras, J. (2002). Autonomia de Professores. Trad. Sandra Trabuco Valenzuela: Cortez.

Cunha, M. I. de. (2014). Pressupostos do desenvolvimento profissional docente e o assessoramento pedagógico na universidade em exame. In: Cunha, M. I. de. (Org.). Estratégias institucionais para o desenvolvimento profissional docente e as assessorias pedagógicas universitárias. Araraquara, SP: Junqueira \& Marin, p. 27-57.

Ferreira, N. S. C. (2006). Formação continuada e gestão da educação no contexto da "cultura globalizada". In: Ferreira, N. S. C. (Org.). Formação Continuada e Gestão da Educação. (2 $2^{\mathrm{a}}$ ed.): Cortez.

Gil. A. C. (2008). Métodos e Técnicas de pesquisa social. (6a ed.): Atlas.

Imbernón, F. (2001). Formação docente e profissional - formar-se para a mudança e a incerteza: Cortez.

Imbernón, F. (2010). Formação continuada de professores: Artmed.

Lei de Diretrizes e Bases da Educação Nacional. Lei nº 9394/96 de 20 de Dezembro de 1996. 2.ed. Brasília: Senado Federal, coordenação de Edições Técnicas.

Lima, M. S. L., \& Pimenta, S. G. (2001). A formação contínua do professor nos caminhos e descaminhos do desenvolvimento profissional. Universidade de São Paulo, São Paulo. https://repositorio.usp.br/item/001183634. 
Research, Society and Development, v. 10, n. 3, e24210313224, 2021

(CC BY 4.0) | ISSN 2525-3409 | DOI: http://dx.doi.org/10.33448/rsd-v10i3.13224

Nóvoa, A. (1992). Coord. Os professores e a sua formação. Lisboa: Dom Quixote. http://hdl.handle.net/10451/4758.

Pereira, A. S., Shitsuka, D. M., Parreira, F. J., \& Shitsuka, R. (2018). Metodologia da pesquisa científica. UFSM. https://repositorio.ufsm.br/bitstream/há ndle/1/15824/Lic_Computacao_Metodologia-Pesquisa-Cientifica.pdf?sequence=1.

Schön, D. A. (1987). Educating the reflective practitioner: Jossey-Bass, p. 355.

Silva, V. L. R. da, \& Cunha, M. I. (2018). Formação e desenvolvimento profissional docente: desafios para o contexto inicial da docência universitária. In: Wiebusch, E. M., \& Vitória, M. I. C. (Org.). Estreantes no ofício de ensinar na educação superior: EDIPUCRS, p.43-63.

Vasconcellos, K. R., \& Bernardo, E. (2016). Profissionalização docente: reflexões e perspectivas no Brasil. Educação \& Formação, 1(2), 208-222.

Veloso. C., \& Sobrinho. J. A. de C. M. (2019). Contribuições da formação continuada na ótica do professor de Ciências Naturais. Revista Retratos da Escola. Brasília, 11(20), 309-321, http://www.esforce.org.br. 